\title{
William Lewis on Gold
}

\author{
THE FIRST METHODICAL ACCOUNT OF ITS \\ CHEMICAL AND PHYSICAL PROPERTIES
}

\author{
L. B. Hunt \\ Johnson Matthey \& Co. Limited, London, U.K."
}

Two hundred years ago, on January 21st, 1781, there died at his home in Kingston on Thames an almost forgotten English chemist who not only had a marked influence on the chemical technology of the Industrial Revolution, but who compiled the first logical and comprehensive account of the chemistry and physics of gold and of its major uses at that time.

William Lewis receives but little attention in the reference books and the histories of chemistry, while the 'Dictionary of National Biography' confuses him with another man of the same name and perpetrates a number of errors in his date of birth and education.

A skilled experimentalist as well as a prolific author and editor, in his time he was the undisputed authority on any subject on which he had written, and his books were relied upon for some of their lecture material by William Cullen and Joseph Black among others and were swiftly translated into German and French.

Fortunately he was rescued from near oblivion some years ago by the painstaking researches into local records and manuscript sources carried out by the late Dr. F. W. Gibbs of the Royal Institute of Chemistry (1).

William Lewis was born in June 1708, the eldest son of a brewer of Richmond, Surrey. He entered Christ Church, Oxford, in 1725 to study medicine, but later moved to Cambridge where he was admitted a Fellow-Commoner at Emmanuel College in 1730, and there he obtained his M.B. degree a year later (2). He then settled in London and very soon became known as a public lecturer on chemistry and on the improvement of pharmacy and the manufacturing arts, subjects that were to occupy him fully for almost the next fifty years.

\footnotetext{
On Wednefday tbe rath Infant, at Fout ' Clock in the Afternoon, at the Elaboratory in New-freet, Fetter-lane,

T JILL begin a COURSE of CHEMISTRY, with a View to the Improvement of PHarmacY, TRADES, and the ART irfelf.

By WILLIAM LEWIS.

Schemes of the Courfe are to be had at Mr. Willock's, Bookfeller, in Cornhill ; and at the Elaboratory.
}

In 1745 he was elected a Fellow of the Royal Society, and in the following year his first two books appeared. These were an abridged version in two volumes of 'Medical Essays and Observations published by a Society in Edinburgh' and a revised edition of the 'Complete Course of Chemistry', first published by George Wilson in 1691, which he brought up to date by the inclusion of new material from the publications of French, German and Dutch chemists.

In 1747 Lewis moved to Kingston, where he rented a large house and equipped it with a first class laboratory. Early in the following year he published a pamphlet, "Proposals for Printing, by Subscription, 'Commercium Philosophico-Technicum': or 'The Philosophical Commerce of Arts', Designed as an Attempt to advance Useful Knowledge". This project was intended to appear as a periodical, with six parts to the annual volume, while he further proposed, by laboratory work, to find uses for materials not as yet employed in manufacture, to enquire into the possibility of replacing scarce or expensive ingredients by cheaper ones and to find ways of using home products to avoid importing materials from the Continent. He had also made arrangements for regular correspondence with chemists in a number of European countries so as to keep his readers more fully informed.

Further consideration of his plans led, however, to a change of intention from publishing a series of miscellaneous articles on manufacturing processes to

Early in his career Lewis became well known as a public lecturer on chemistry and its applications in industry. This advertisement for one of his courses of lectures was published in the London Daily Post on January 11th, 1737 
The title page of the 'Commercium PhilosophicoTechnicum', dedicated to King George III and published on April 7th, 1763

\section{$C O M M E R C I U M$}

\section{Pbilofophico-Tecbnicum;}

O R, T H E

\section{Philosophical Commerce}

O F

\section{A $\quad$ R $\quad$ T $\quad$ S : \\ DESIGNED AS}

AN ATTEMPT TO IMPROVE

Arts, Trades, and Manufactures.

\begin{tabular}{c}
\hline By W. LEWIS, M. B. and F.R.S. \\
\hline Fiat Experimentum. BAcoN. \\
\hline
\end{tabular}

The frontispiece of the book shows the laboratory of an eighteenth century experimentalist, based upon Lewis's own laboratory. The chemical apparatus is shown in the centre, the melting furnaces on the left and the mechanical and physical instruments to the right. This was one of the earliest laboratories specifically designed for research in applied chemistry and physics

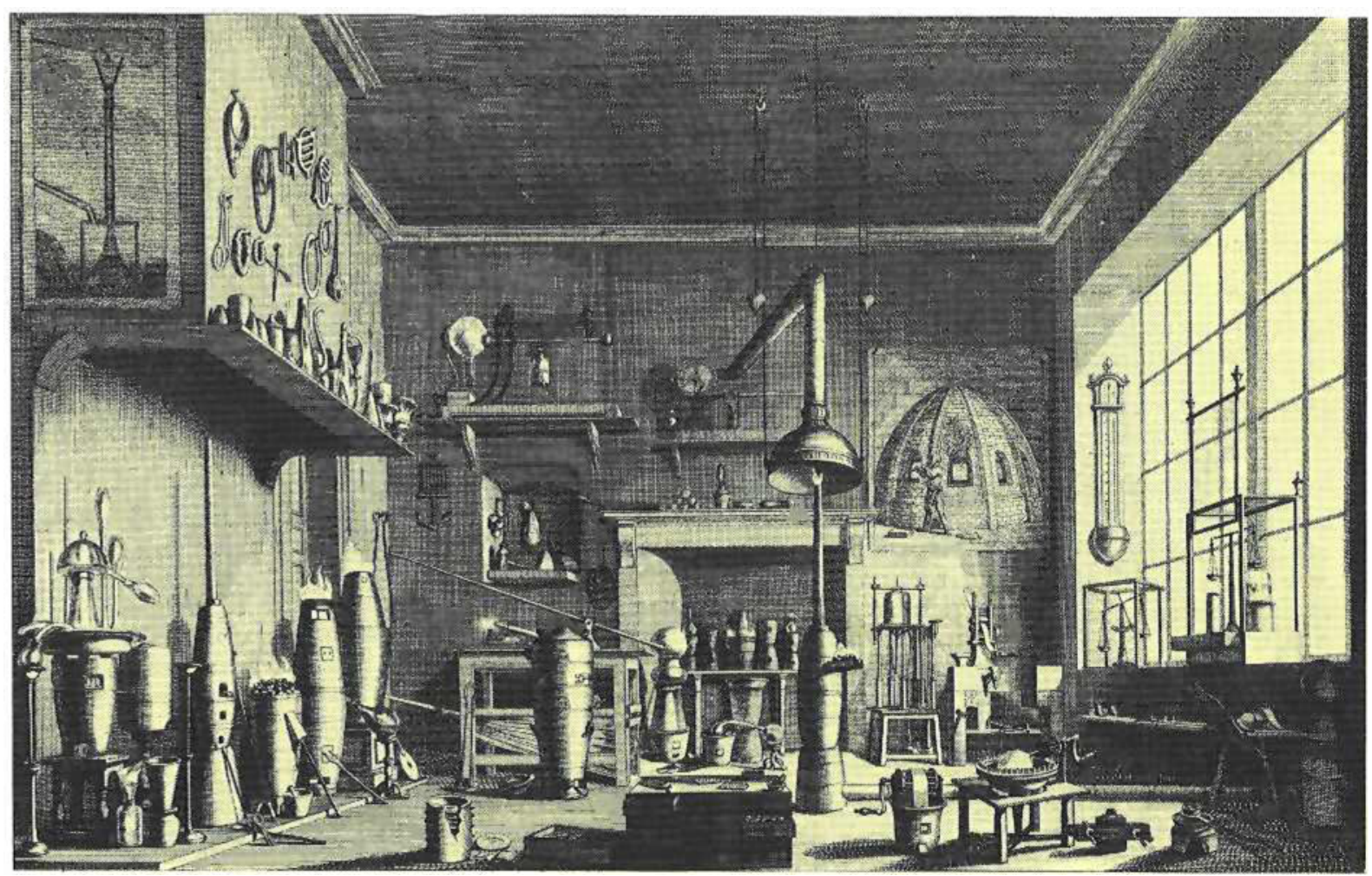

Gold Bull., 1981, 14,(1) 
giving accounts of 'the invariable properties of matter', and this naturally brought about a delay, as well as the need for some assistance in the work. To recruit a suitable person was not easy, and it was not until 1750 that he engaged Alexander Chisholm, a young graduate from Aberdeen. Chisholm had travelled to London in search of employment, and * soon after his arrival he noticed a Greek book placed open in a bookseller's window and stopped to read it. Lewis happened to be in the shop and, impressed by the young man's appearance, called him inside and after some conversation engaged him as his laboratory and literary assistant (3). Fortunately Chisholm was to prove an energetic and painstaking helper and soon acquired a sound understanding of chemistry, while his knowledge of French, German and Swedish was of great value to Lewis in studying the work of foreign chemists.

\section{Award of the Copley Medal}

For some years they were intensely occupied with the study of chemistry and pharmacy, and then with a long series of experiments on the newly discovered platinum and on its alloys with most of the other metals then known (4). For this work, and especially for his study of the methods of analysis and separation of alloys of gold and platinum, Lewis was awarded the Copley Medal of the Royal Society, the highest scientific award at that time, in 1754.

Other work still further delayed the publication of the 'Commercium Philosophico-Technicum'. In 1759 Lewis published 'Chemical Works of Caspar Neumann Abridged and Methodised with Large Additions, Containing the later Discoveries and Improvements Made in Chemistry and the Arts Depending thereon'. Neumann (1683-1737) had been professor of chemistry in Berlin, and Lewis's edition remained a work of reference until well into the nineteenth century.

Next came another pharmaceutical work, 'An Experimental History of the Materia Medica', published in 1761. This contained a considerable amount of original work by Lewis, including a rather scathing comment on aurum potabile:

'That the aurum potabile of the faculty of Paris, reckoned one of the best of the preparations of this kind, (made by shaking some oil of rosemary with a solution of gold in aqua regia, and afterwards digesting the oil for a month in rectified spirit of wine) retains none of the gold, is obvious from the characters of this metal above laid down.'

In the same year Lewis again announced his intention of publishing the 'Commercium PhilosophicoTechnicum', and the first part duly appeared in 1763. The work was dedicated to King George III, to whom, when Prince of Wales, Lewis had given private lectures in his mother's palace at Kew. The first thirty-odd pages comprised a detailed description of the laboratory of an experimental chemist and particularly of the design of his furnaces on which matter he acknowledged:

'a hint from an ingenious workman in gold who employed, as a melting furnace, two of the larger kind of black pots, one inverted over the other.'

But by far the largest section of this first volume, some 192 pages, was devoted to the physics, chemistry and applications of gold.

This opens, as illustrated here, with a description of the colour of gold and the ease with which any surface discolouration can be removed. This is followed by detailed accounts of the preparation of gold leaf, of wire drawing, and of the gilding of metallic and nonmetallic objects with gold leaf.

The work progresses in what we should now regard as a rather inverted order, from the ductility of gold and the manufacturing arts depending on this property, to its melting and alloying, its resistance to corrosion by acids, its assaying and refining, and finally to the sources of gold and its extraction.

The section on alloying opens with a rather charming paragraph:

'The repugnancy or contrariety which obtains in sundry instances, between different metallic bodies made fluid by fire, and which is no less strongly marked than that betwixt oil and water, is nowhere observed in regard to gold; this metal uniting readily with all the other known metallic bodies, and seeming to have a strong, though not equal, affinity to them all.'

He was aware, well over a century before it was clearly established by the early metallurgists, of the depression of the melting point of a metal brought about by alloying:

'All the metals, which melt easier than gold, dissolve it in a less heat than the gold would melt in; and gold, brought into fusion, dissolves in like manner those which are more difficultly fusible.'

\section{The Alloying Properties of Gold}

The major part of this section deals with the alloys of gold with silver, copper and platinum, and the alterations produced by varying amounts of alloying additions. He appreciated the technique of soldering with gold-copper alloys:

'Two pieces of fine gold are soldered by gold that has a small admixture of copper; and gold alloyed with copper is soldered by such as is alloyed with more copper: the workmen add a little silver as well as copper, and vary the proportions of the two to one another, so as to make the colour of the solder correspond, as nearly as may be, to that of the piece.'

The brittleness occasioned by additions of tin, lead, zinc and bismuth to gold is well documented, as 
always both from published work and from his own experiments.

A further section covers the alloying of gold for coinage and the varying practices of the mints of European countries and of China and Japan, followed by the use of touch needles to assess carat standards, the use of the specific gravity method of estimating the composition of an alloy and then by a full treatment of methods of assaying by cupellation with lead and by parting with nitric acid. Then comes a section on refining, beginning, with a clear sense of commercial values:

"The processes described in the preceding section, for the assaying of gold, are used also for refining it in the way of business; with such variations, in the manner of conducting them, as the greater quantities operated upon, and the requisite cheapness and dispatch, render necessary.'

This includes full descriptions not only of the refining of relatively pure gold, but also of the separation of gold occurring in small amounts in silver, platinum, and copper and other base metals.

Lewis's understanding of the mineralisation of gold is shown in the opening paragraphs of the next section on its occurrence and extraction:
Finally, in a chapter headed 'Of the Alchemical History of Gold' Lewis displays a most healthy scepticism on the possibility of transmutation from base metals and deserves one last quotation:

'If these pretensions were proposed as a matter of speculation only, I believe no one, who has at all considered the nature of metals, could hesitate in pronouncing them absurd.'

This closed the first part of the 'Commercium Philosophico-Technicum'. Parts II, III and IV of the work appeared two years later, in 1765, and dealt with colours and pigments, and also gave a full account of all the work that had been done on platinum up to that time. A bound volume of these parts was then published under the date 1763. A further part on the metallurgy of iron, for which both Lewis and Chisholm had done an enormous amount of investigation and had travelled to many works in the Midlands of England, was never to appear, although much of it exists in manuscript form.

Lewis was not alone among the compilers of handbooks or encyclopedias on the relations of science to the manufacturing arts, but he stood head and shoulders above both his predecessors and his contemporaries, mainly because he added to his

'Gold is found in its perfect metallic state; sometimes in masses of considerable magnitude; more frequently in dust or minute grains, intermingled among earths and sands; or in little drops and veins, bedded in different coloured stones which strike fire with steel, and are not soluble in aqua fortis. It is never debased into a true ore, as other metals generally are by the coalition of arsenical or sulphureous bodies.'

His account of extraction procedures is of course confined to alluvial gold, but in detail of description of both panning and of treatment with mercury it would be creditable in a writer a century later.

The opening page of the long section of the 'Commercium Philosophico-Technicum', which the author devoted to the properties and applications of gold

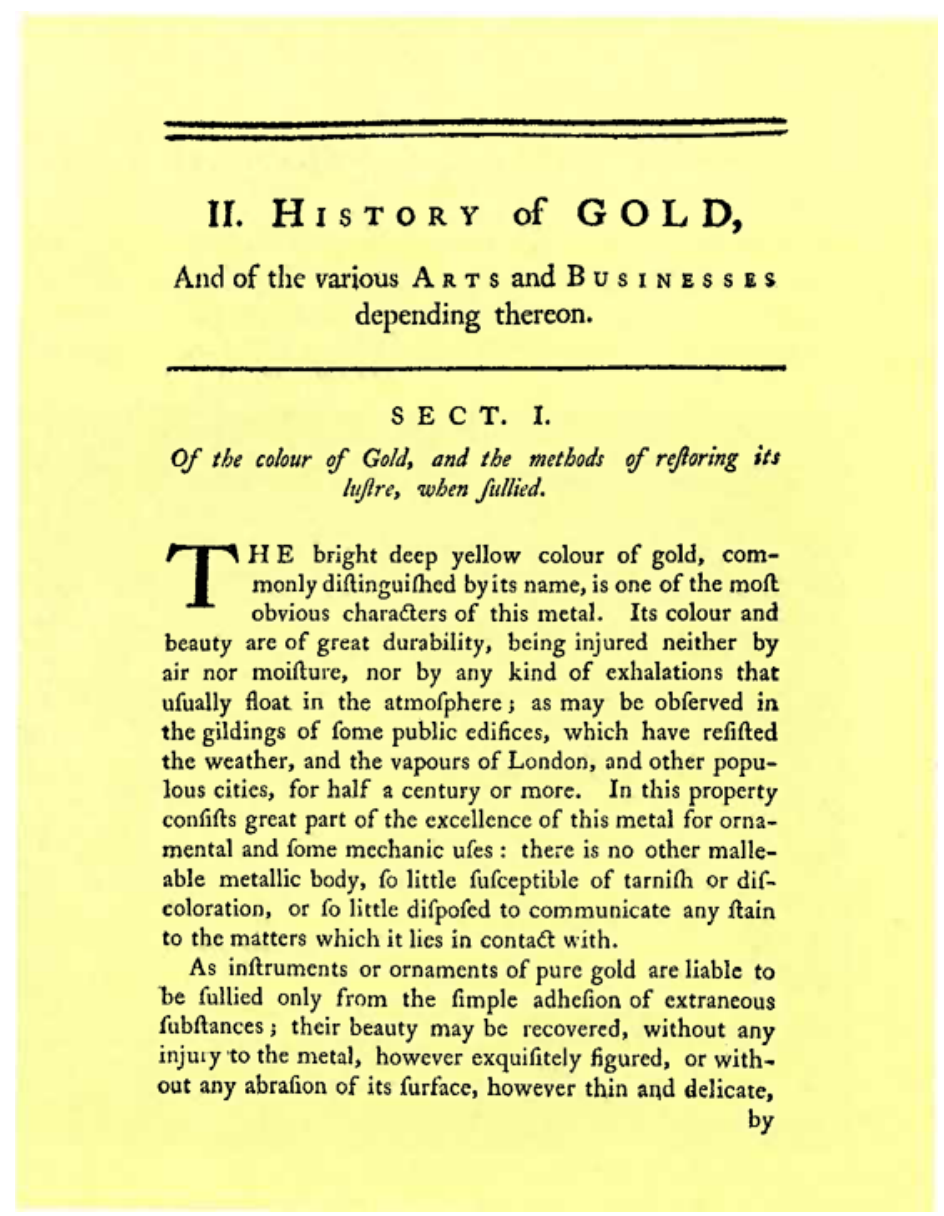


very wide reading a skill in experimentation and a clear understanding of the chemical and physical theories of his time. He emphasized, in fact, that there were two distinct sciences concerned with the properties of materials, physics and chemistry.

The famous 'Encyclopédie' of Diderot and d'Alembert, published in Paris between 1751 and 1780 , devoted only some ten pages to gold, and much of the information was out of date, while Robert Dossie's 'The Handmaid of the Arts' and 'The Elaboratory Laid Open', both published in London in 1758 , lacked a great deal of essential detail, as did John Barrow's 'A New and Universal Dictionary of Arts and Sciences' of 1751 and Peter Shaw's 'Chemical Lectures for the Improvement of Arts, Trades, etc.', first published in 1731 and in a second and improved edition in 1761 .

The first part of Lewis's work, the section on gold, which differed widely from these publications, was well reviewed in a number of journals and was immediately translated into German by one of his correspondents, J. H. Ziegler of Winterthur in Switzerland, and by J. G. Krünitz of Berlin (5), while the whole volume was published in French in 1768 , translated by de Puisieux (6).
The complete work, which Gibbs described as 'a classic in the literature of chemical technology' was consulted for the next three quarters of a century. Even as late as 1880 the great John Percy, professor of metallurgy at the Royal School of Mines in London, referred to Lewis's book as 'a volume, often to be had for an insignificant sum, but rarely appreciated as it ought to be ... it contains much information both of scientific interest and of practical value and if its merits were known it would, I think, be more in request than it is' (7).

\section{References}

1 F. W. Gibbs, 'William Lewis, M.B., F.R.S. (1708-1781)', Ann. Sci. $1952,8,122-151$

2 J. A. Venn, 'Alumni Cantabriqienses', Vol. I, Part III, 1924, p. 82

3 T. Thomson, 'History of Chemistry', Vol. I, 1830, p. 266

4 W. Lewis, Philos. Trans., 1754, 48, (2), 638-689; 1757, 50, (1), 148-166

5 J. H. Ziegler, 'Historie des Goldes und der verschiedenen Künste und Gewerbe, welche darvon abhängen', Zürich, 1764 J. G. Krünitz, 'Phys.-chym. Abhandlungen und Versuche zur Beförderung der Künste, Handwerke und Manufakturen', Berlin, 1764-66

6 'Expériences physiques et chymiques, sur plusieurs matières relatives au Commerce et aux Arts, traduit par M. De Puisieux', 3 vol., Paris, 1768/9

7 J. Percy, 'Metallurgy; Silver and Gold'; Part I, London, 1880, p. 181 